\title{
Self-Referentiality in Kant's Transcendental Philosophy
}

\author{
Claude Piché, Montréal, Canada
}

In the ongoing debate concerning transcendental arguments, Rüdiger Bubner emerges as one of the few who attempt to justify the strategy espoused by Kant in his Transcendental Deduction by insisting on its self-referentiality. This special type of self-reflexivity at work in Kant's transcendental argumentation is inescapable when one considers the specificity of the critical project. If this project aims at stating the conditions of the possibility of empirical knowledge, its discourse will be self-referential to the extent it proves itself to be regulated by the very concepts that are found to be constitutive $a$ priori of the empirical experience. In Bubner's words:

If it becomes apparent that even reasoning about factual forms of knowledge and the clarification of their preconditions is not possible without making use of certain elements of that form, then it is not a merely factual state of affairs which is demonstrated. Rather, it is a logical then it is not a merely factual state of affairs which is demonstrated. Rather

In fact, Kant cannot avoid this recourse to a self-referential confirmation of his developments if he wants to remain faithful to the goal of the Critique of Pure Reason. The express purpose of the Critique being the examination of the pretensions of dogmatic metaphysics, Kant cannot in the end refute them while adopting a standpoint identical to the one of the metaphysicians. In other words, as Bubner has clearly shown, critical philosophy cannot raise any claim to an ultimate foundation. ${ }^{2}$ There is no such thing, in Kant, as a self-evident first principle that would support a deductive system of dogmatic truths. This would be the equivalent of providing philosophy with an absolute starting point, which is - and for good reasons - out of the question for Kant. If he is to avoid the pitfalls of an infinite regress in the chain of conditions, he is left with no alternative but to have recourse to another strategy: self-referentiality.

In what follows, I would like to broaden the scope in which self-referentiality becomes operative in the Critique of Pure Reason. Bubner, for his part, restricts the application of this form of self-reflexivity to the Transcendental Deduction of the categories. He sees in the concept of "synthesis" the key to the self-reference present in transcendental philosophy. The deduction of the categories establishes that the empirical synthesis of the manifold of sense-data presupposes a pure form of synthesis that is expressed by the transcendental unity of apperception. The philosophical discourse that uncovers this link between the two kinds of synthesis does nothing but relate them with the aid of a further synthesis. ${ }^{3}$ Bubner admits however that the textual evidence demon- 
strating that the argumentation of the Transcendental Deduction itself operates by way of a synthesis is rather meager. For my part, I would like to consider the finished products of Kant's Critique of Pure Reason, namely the transcendental principles of the Analytic, in an attempt to illustrate just how far the content of those a priori synthetic judgments is also valid mutatis mutandis for the transcendental discourse as such. For reasons that will soon become obvious, I shall focus my attention on what can be considered as the main principle of Kant's table: the law of causality. I shall try to make clear how the famous "conditions of the possibility of experience" exposed in the Transcendental Analytic are subject to restrictions similar to the ones they impose in the field of experience.

The first thing that must be clarified is the status of the expression "possible experience" which constitutes, according to Kant, the main point of reference of all our cognitive pretensions. As we know, possible experience becomes the ultimate criterion for the truth of every synthetic proposition whatsoever. In the context of Kant's Analytic, the expression "possibility of experience" has a twofold meaning: first, synthetic judgments a priori have to relate, for their objective validity, to a possible empirical experience because otherwise they would be deprived of any truth claim; second, the synthetic $a$ priori propositions of the Analytic render experience itself possible, so that they are, conversely, necessary conditions of its very possibility. However, beyond those two complementary readings of the experience as "possible", it must not be forgotten that in both cases, experience is a mere possibility. For something to be possible, means that it is not itself necessary. In a passage of the Doctrine of Method in which Kant exposes the particular nature of a philosophical proof, the mere "contingency" of experience is explicitly stated.

Now in the whole domain of pure reason, in its merely speculative employment, there is not to be found a single synthetic judgment directly derived from concepts... Through concepts of understanding pure reason does, indeed, establish secure principles, not however directly from concepts alone, but always only indirectly through relation of these concepts to something altogether contingent [zufällig], namely, possible experience. ${ }^{4}$

How are we to interpret this "contingent" status of experience? Taken formally, the concept of contingency simply means that a thing's not-being is thinkable. However Kant goes on to say that the concept of contingency must be understood in terms of the category of relation, so that it can be better grasped by us when brought into connection with a cause: “...we recognize contingency in and through the fact that something can exist only as the effect of a cause." It must be reminded that this definition of contingency is taken from the "General Note on the System of the Principles" and that it is valid for effects produced within the experience, and is, therefore, not automatically suited to qualify the status of experience taken as a whole (überhaupt), which is the case we are now considering. We have to see then, if we can establish a parallel between the status of the "causes" which produce effects in experience and the "conditions" that are required for the contingent experience to occur at all.

Contingent experience leads us hence to the question of its conditions and, in particular, of the theoretical status of these. Let us then, consider more closely the very nature of those conditions of experience. A partial answer is given to us in the sentence stating the central thesis of the Transcendental Deduction (in the first edition): "The a priori conditions of a possible experience in general are at the same time conditions of the possibility of objects of experience." I say that this is an incomplete answer because Kant refrains from putting a definite article in the second part of the sentence: "The a priori conditions...are...conditions of the possibility." This simply means that the a priori conditions of empirical knowledge do not represent the complete range of conditions required for this kind of knowledge. As the sentence following our quote indicates, Kant is alluding here solely to the formal conditions of experience: i.e. the spatio-temporal determinations exposed in the Transcendental Aesthetic, as well as, the categorial determinations a priori whose validity is under scrutiny in the Deduction. This amounts to saying that Kant considers a second set of conditions that must also obtain if we want to have experience in general. These are the material conditions that provide the pure forms of knowledge with content: the sense-data accessible to us through sensation. The two sets of conditions being different in kind (pure/empirical, a priorila posteriori), how do they relate to each other? Is the mere presence, side by side so to speak, of both sets of conditions sufficient to give rise to experience? We will find an answer to these questions if we turn to the transcendental status of the conditions of the possibility of experience in general.

Surprisingly, Kant declares that the conditions a priori of the possibility of experience (at least in a specific sense that remains to be clarified) are no less "contingent" than experience itself! This comes, to a certain extent, as a surprise, considering the aim of the Critique of Pure Reason which is to delineate the full domain of human knowledge from a transcendental point of view. Is it plausible that Kant might have been satisfied with mere contingent conditions? In any case, this would still remain well in accordance with his consciousness of the finiteness of this human knowledge. A finiteness the philosopher himself cannot transcend. To stress the contingency of these a priori conditions is consistent with a transcendental foundation of knowledge for which the adoption of an absolute standpoint is prohibited.

The passage to which I would like to draw attention in this matter is taken from the introductory remarks to the Analytic of the Principles. It states the contingent character of the dynamic principles in the following way:

The a priori conditions...of the existence of the objects of a possible empirical intuition are in themselves only contingent [zufällig].... The principles... of dynamical employment will also indeed possess the character of a priori necessity, but only under the condition of empirical thought in some experience, therefore only mediately and indirectly. 
Those well acquainted with these lines will have noticed that I have omitted in my reading the mentions concerning the mathematical principles which are, precisely in this case, declared "absolutely necessary" and not contingent. Given the space constraints, I am obliged to limit myself to a few remarks on the subject of the privileged status of the dynamic over the mathematical principles in the transcendental argumentation. ${ }^{8}$ Both mathematical principles prepare for experience as such, but they deal solely with the extensive and intensive magnitudes of its object in the intuition. They are therefore devoted, in accordance with their titles, to "intuition" and to a merely "anticipated" perception, whereas the dynamical principles focus upon the empirical element of experience insofar as sensation must first occur if the object of our knowledge is to be a real one, an existing one. The Analogies of Experience are "regulative" and not "constitutive" in the sense that they can only regulate the existence of an object which is instantiated exclusively through sense-data that are outside the control of the transcendental subject. ${ }^{9}$ It is no wonder then, Kant begins to associate the word "experience" only with the title of the Analogies, for experience really involves this empirical component that can be furnished solely by sensation. In view of this, the mathematical principles are certainly constitutive of the intuition (by anticipating its spatio-temporal form and its intensity) and, for this reason, they are "absolutely necessary" to this intuition. They philosophically found mathematics as a discipline. However, it might be added that this discipline ultimately owes its objective validity to the reference to empirical experience. $^{10}$

If we are ready to concede a privileged role to the dynamical principles and, in particular, to the Analogies, what are the consequences of their proclaimed "contingent" status as conditions a priori of the possibility of experience? It simply means that while they might well be necessary conditions, conditiones sine qua non, they are nevertheless in themselves conditioned, dependent on something else, on another condition. Not only are the a priori conditions of the possibility of experience insufficient for the taking place of experience (the a posteriori conditions are also required), they are not in themselves selfsufficient. They are not causa sui, to borrow a formula from Spinoza, whose philosophy Bubner considers to be the paradigm of every project aiming at an ultimate foundation. ${ }^{11}$ The a priori conditions of experience are not, for Kant, the attributes of an absolute subject. If the knowing subject cannot be declared absolute, "ir-relative" so to speak, this means that he/she is essentially relative, he/she is in a fundamental relationship to something else. In the present case, Kant's transcendental subject enters into a relation with another set of conditions of experience, the empirical conditions. He/she depends on them for setting up an experience in general; while disposing over the a priori conditions of experience, he/she is dependent on an heterogeneous order of conditions. Our quote above designates them as "the condition of the empirical thought".
As opposed to Fichte's " $\mathrm{I}$ " then, Kant's transcendental subject is not an unconditioned subject. He/she is essentially "restricted to conditions" while an absolute subject would suffer from no such impediment. ${ }^{12}$ Consequently, his/her cognitive operations in the field of experience are contingent; they cannot even be conscious to him/her, unless he/she is solicited, that is "affected", by the empirical data

We can now raise the question of the self-referentiality of Kant's transcendental foundation of knowledge. We have seen that the contingency of experience has led us to the problem of the contingency of the a priori conditions of the possibility of experience. Due to the fact that contingency for Kant can best be understood in terms of causality, it has become clear that, if self-referentiality is to be more than an empty word, the Kantian transcendental argumentation should present certain affinities with the Second Analogy of Experience. According to this dynamic principle, nothing occurs in the world without having been caused by something else. Every single effect is contingent, and the cause of each effect is in its turn contingent, and so on. For example, the pain in my finger is caused, if I may paraphrase a famous example in the Prolegomena, by the warmth of the stone that I touch, this warmth being itself caused by the light of the sun, etc. If the link between the cause and the effect is necessary, the elements related are never in themselves necessary. The necessity applies only to the relation between A and B, neither A nor B is itself ever necessary. For this reason, Kant claims that within experience we never attain more than "hypothetical" necessity according to the logical form: if...then. ${ }^{13}$ The consequence is realized only in the hypothetical case that the antecedent obtains, and so on. The problem raised by the infinite chain of causes is dealt with, as we know, in the third Antinomy, and Kant indicates in his critical solution that in experience a cause is never met with that would be "unconditioned". In the same way, the solution to the fourth Antinomy states that never a being can be met which in its own substance could be declared absolutely necessary. To what extent those warnings directed against the dogmatic metaphysicians remain valid for Kant's own transcendental discourse becomes obvious, as soon as we make the appropriate transposition to the broader problem of the conditions of experience in general. The Analytic does not raise the question of the "causes" of knowledge but rather of its "conditions". However the teaching of the principle of causality, namely the mere contingency of each and every cause, remains valid, the concept of an absolutely necessary cause being incomprehensible to us. As a matter of fact, the two sets of conditions required for the possibility of experience do not compose a chain. With regard to their common product, experience, their conditioning is mutual rather than unilateral, circular rather than linear. There is no experience without sense-perception, and conversely, there is no experience without the application of categories. The conditioning of the empirical and the transcendental 
conditions of knowledge being reciprocal, the two sets of conditions do not constitute separate strands. They must interact if experience is ever to take place.

As in any analogical transposition, there is a danger of ignoring the differences between the levels of discourse involved. While the principle of causality rules our daily experience, the transcendental Analytic purports to establish once and for all the complete range of conditions entering into the formation of this experience. If we are inattentive to this differentiation of levels, we might precisely extrapolate this causal necessity in experience and naturalize the transcendental subject. For this reason, we must insist on the fact that while the transcendental subject might well be "conditioned" in his/her cognitive task by the empirical conditions, this does not amount to saying that he/she is determined by them. The principle of causality first has to be applied. This can only occur in a synthetic judgment-with an a priori component - that requires the freedom of the faculty of judgment, in the transcendental meaning of the word. This only makes more obvious the tremendous difficulty of the Kantian transcendental argumentation insofar as the transcendental subject comes under the yoke of rules that are, all appropriate transpositions having been made, the same as the ones he imposes on the course of nature. Those transcendental laws of man's finite knowledge remain valid for a subject that freely recognizes them as binding mutatis mutandis for his own philosophical investigation. This is the sense in which we can say that the lessons of Transcendental Analytic are selfreferential: they regulate the discourse that brings them to light.

Against Humean skepticism Kant tries to demonstrate that the concept of causality is a part of the a priori conditions of experience, whereas he constantly reminds the dogmatic metaphysicians of the necessity for human knowledge in general to relate to the empirical conditions of experience. The results of the Analytic of the Principles have led him to refuse any kind of unconditioned necessity in experience and, for himself as a philosopher, any selfevident ultimate principle. In addition, they have led him to repudiate all cognitive claim concerning a necessary being, which was to be the cornerstone of metaphysics in the form of the cosmo-ontological argument. Kant accuses the rationalist metaphysicians of not having investigated closely enough the conditions of experience and, consequently, of not having discovered in experience the point of reference of all human knowledge. On the contrary, their metaphysics always aims at detaching itself from the sensible world. Rational psychology is only interested in the soul apart from sensibility, ${ }^{14}$ and rational theology, in its highest degree of abstraction, is preoccupied with a selfsufficient transcendent being. ${ }^{15}$ According to Kant, the only safeguard against metaphysics resides in the obligatory reference to the possibility of experience, the possibility of which the first Critique has employed all appropriate means to explain. Were it not for their aim of explaining experience, these means would be void of any legitimacy because they inevitably transcend the limits of their object of investigation. Transcendental philosophy is valid as a second-order investigation only insofar as it is devoted to the explanation of a first-order discourse, namely empirical experience. Indeed, one could altogether reject the transcending dimension of "transcendental" philosophy and criticize Kant for not having respected the limitations of knowledge stated in the Critique. This attack against Kant's achievement was effectively made in the immediate aftermath of the publication of the Critiques by G. E. Schulze in his Aenesidemus. In his eyes, philosophical explanation should take place in the first-order discourse of our knowledge of natural phaenomena in accordance with Kant's own delimitation. Due to his psychologistic bias, he rejects Kant's second-order investigation and condemns the whole critical undertaking as being on the same level as the dogmatic metaphysics it wishes to denounce. ${ }^{16} \mathrm{We}$ have discovered, for our part, that transcendental discourse is legitimate, as long as, it is constantly bound to the question of the possibility of experience and the transcendental laws remain, on this higher level, normative of philosophical investigation itself. Schulze could not be receptive to the self-referential dimension of the Analytic, because he completely misinterprets the transcendental subject as an "absolute subject". 17

While this self-referentiality is not treated explicitly in Kant's Critique, its tacit acceptance could nevertheless explain why certain further moves in Kant's investigation do not seem to pose any particular problem to him. Let us think, for instance, of the question of the thing in itself. Kant shows no reluctance to make it part of his strategy of explaining the conditions of possibility of experience. He assumes it to be "real" (wirklich) although strictly "unknowable". ${ }^{18}$ The thing in itself is a "correlate" of the phaenomenon that "corresponds" to it in the sensible world, ${ }^{19}$ and, in this context, the use of the category of cause remains unproblematic, as long as, it is related to the goal of explaining the possibility of experience. This raises no specific difficulty since, as Kant himself admits, we never refer to that thing in itself in our daily experience. ${ }^{20}$ The concept belongs exclusively to the transcendental level of investigation, and, therefore, Kant can feel perfectly at ease to make use of it. We could even ask further questions in regard to the transcendental extension of the dynamic principles by addressing the problem of community. ${ }^{21}$ In the same manner as the empirical subject establishes a relation of community with the empirical spatial objects, ${ }^{22}$ the transcendental subject is necessarily led to consider him/herself in relation to a counter-part, namely the "transcendental object" (at least where this expression is synonymous with the thing in itself). ${ }^{23}$ We could push further this examination and try to trace the self-referentiality of the transcendental principles in the whole of Kant's transcendental apparatus. In the end, the self-referential character of a discourse stating the conditions of finite knowledge reveals itself to be the only appropriate answer to Hegel's famous 
"dialectics of the limit", according to which a philosophy that, like Kantian criticism, identifies the limits of knowledge has already surpassed them and reached the standpoint of the infinite.

\section{Notes}

1. Rüdiger Bubner, "Kant, Transcendental Argument and the Problem of Deduction," The Review of Metaphysics 28 (1975): $464-465$ (our emphasis). This is the slightly revised version of a paper originally given in German under the title "Zur Struktur eines transzendentalen Arguments," Akten des 4. Internationalen KantKongresses Mainz 1974, ed G. Funke (Berlin/New York: de Gruyter, 1974) 15-27. For other uses of selfreferentiality in the discussion concerning transcendental arguments, see Marcel Niquet, Transzendentale Argumente. Kant, Strawson und die sinnkritische Aporetik der Detranszendentalisierung (Frankfurt: Suhrkamp, 1991) 83 .

2. Rüdiger Bubner, "Kant, Transcendental Argument and the Problem of Deduction", 26; see also his article "Selbstbezüglichkeit als Struktur transzendentaler Argumente," Kommunikation und Reflexion. Zur Diskussion der Transzendentalpragmatik, ed. W. Kuhlmann and D. Böhler (Frankfurt: Suhrkamp, 1982) 322. The original (and shorter) version of this text was later published in Bedingungen der Möglichkeit. 'Transcendental Arguments' und transzendentales Denken, ed. E. Shaper and W. Vossenkuhl (Stuttgart: Klett-Cotta, 1984) 63-79. Against Bubner, Wolfgang Kuhlmann asserts that Kant seeks to establish an ultimate foundation, see his "Was spricht heute für eine Philosophie des kantischen Typs?," Kant und die Transzendentalpragmatik (Würzburg: Königshausen \& Neumann, 1992) 13.

3. Rüdiger Bubner, "Kant, Transcendental Argument and the Problem of Deduction," 466-467. In his book Sprachanalyse und Transzendentalphilosophie (Stuttgart: Klett-Cotta, 1982), Reinhold Aschenberg deplore the poverty (Dürftigkeit) of the outcome of Bubner's discussion on the central role played by the "synthesis" in Kant's transcendental argumentation, see p. 305. Wolfgang Becker follows a similar line of criticism in his "Kritik und Begründung in transzendentaler Argumentation," Kant-Studien 76 (1985): 171.

4. Immanuel Kant, Critique of Pure Reason, trans. N. Kemp Smith, A736-737/B764-765.

5. Kant, Critique of Pure Reason, B 291; see further A459-460/B487-488: "In the strict meaning of the category, the contingent is so named because its contradictory opposite is possible. Now we cannot argue from empirical contingency to intelligible contingency. When anything is altered, the opposite of its state is actual at another time, and is therefore possible. This present state is not, however, the contradictory opposite of the preceding state. To obtain such a contradictory opposite we require to conceive, that in the same time in which precedingste. To the preceding state was, is opposite could have existed inits place, and of] the alteration.... Alteration proves only empirical contingency, that is, that the new state, in the absence of a cause which belongs to the preceding time, could never of itself have taken place. Such is the condition prescribed by the law of causality."

6. Kant, Critique of Pure Reason, A111. The same is true of the formulation of A158/B197.

7. Kant, Critique of Pure Reason, A160/B199-200 (translation modified).

8. For the central place of the Analogies in Kant's transcendental argumentation, see Konrad Cramer, "A Note on Transcendental Propositions in Kant's Critique of Pure Reason," Transcendental Arguments and Science, ed. P. Bieri et al. (Dordrecht/Boston/London: D. Reidel, 1979) 37-43.

9. Kant, Critique of Pure Reason, A178-179/B221-222.

10. Kant, Critique of Pure Reason, A157/B196; see also A223-224/B271, A239-240/B298-299. For this point, the reader may consult Paul Guyer, Kant and the Claims of Knowledge (Cambridge: Cambridge University Press, 1987) 188.

11. Rüdiger Bubner "Selbstbezüglichkeit als Struktur transzendentaler Argumente," 323.

12. Kant, Critique of Pure Reason, A326/B382. In this respect, Robert Pippin defines the a priori conditions of experience as having only a "conditional validity". "The Idealism of Transcendental Arguments," Idealistic Studies 18(1988): 101.

13. Kant, Critique of Pure Reason, A228/B280.

14. Kant, Critique of Pure Reason, A342-343/B400-401.

15. Kant, Critique of Pure Reason, A631/B659.
16. "Mit einem Worte also: Was wider die Realität der Einsichten gilt, welche die rationale Psychologie, Kosmologie und Theologie verheisst; das gilt auch wider die Wahrheit der Einsichten, welche die Erklärung des Ursprungs der notwendigen synthetischen Sätze aus dem Subjekte des Vorstellens verspricht, und diese Erklärung ist mit allen ihren Beweisen und Gründen, so wie sie in der Vernunflknitik aufgestellt worden sind nichts weiter als eine Sophistikation, deren Schein sogleich verschwindet, als man die nach der kritischen Philosophie einzig wahren Bestimmungen der Begriffe des Verstandes und der Vernunft gehörig kennen gelernt hat." Gottlob Emst Schulze, Aenesidemus oder über die Fundamente der von dem Herrn Professor Reinhold in Jena gelieferten Elementar-Philosophie (rpt. Berlin: Reuther \& Reichard, 1911) 130. For all these questions, see the excellent presentation in Frederick C. Beiser's The Fate of Reason. German Philosophy from Kant to Fichte (Cambridge/London: Harvard University Press, 1987) 280-284. Here I borrow from Beiser the distinction between "first-order" and "second-order" investigation.

17. G. E. Schulze, Aenesidemus, 127, $129,130$.

18. Kant, Critique of Pure Reason, BXX

19. Kant, Critique of Pure Reason, A30/B45; A143/B182.

20. Kant, Critique of Pure Reason, A30/B45.

21. The categories of substance and accident do not represent in themselves a relation, but a mere B230.

22. Kant, Critique of Pure Reason, A213/B260.

23. See for example Kant, Critique of Pure Reason, A 494/B 522 